\title{
Teaching English Idioms to Chinese EFL Learners: A Cognitive Linguistic Perspective
}

\author{
Yi Guo ${ }^{1}$ \\ ${ }^{1}$ Post-Doctoral Research Center, Shanghai International Studies University, Shanghai, China \\ Correspondence: Yi Guo, Post-Doctoral Research Center, Shanghai International Studies University, Shanghai, \\ China.
}

Received: March 13, 2019 Accepted: April 16, $2019 \quad$ Online Published: April 18, 2019
doi: 10.5539/elt.v12n5p145
URL: https://doi.org/10.5539/elt.v12n5p145

\begin{abstract}
Learning idioms has always been difficult for L2 learners of English. Drawing on a cognitive linguistic perspective of idiom learning, this paper reports on an empirical study that investigated the effects of incorporating the knowledge of conceptual metaphor and metonymy in L2 classroom instruction of English idioms. The study confirmed the efficacy of applying the conceptual metaphor- and metonymy-based ways of teaching to Chinese college-level EFL learners. It further revealed the different degrees of teaching effect towards different types of metaphoric idioms. While no significant progress was made in learning orientationally and ontologically metaphoric idioms, students benefited more from the conceptual metaphor-based method in learning structurally metaphoric idioms. These findings serve to enrich L2 idiom pedagogy and provide EFL learners with strategies other than "rote memorization" in the process of idiom learning.
\end{abstract}

Keywords: English idioms, teaching, metaphor, metonymy

\section{Introduction}

Idiom is an indispensable part of almost all the languages in the world. For L2 English learners, a good command of idioms convincingly demonstrates a high level of language proficiency. Yet, we are all familiar with the challenge that idioms have posed for L2 learners. Celce-Murcia and Larsen-Freeman (1999) described idioms as "notoriously difficult" (p. 39). A considerable amount of research has showed that L2 learners struggle with idioms in both comprehension and production (Irujo, 1986; Cooper, 1999; Liontas, 2003). Despite the efforts made in idiom teaching practices, we are still in the initial stages of understanding the acquisition of idioms by nonnative speakers (Zyzik, 2011).

Under the traditional view that treats idioms as fixed multiword units, it is difficult for both L2 teachers and students to find out effective ways to deal with English idioms. Hence, what we are facing first is to attempt to search for a proper theoretical framework that can break through the traditional noncompositional approach. Cognitive Linguistics (CL) facilitates such an attempt. In recent decades, the thriving of CL has fruitfully inspired English idiom studies. Many scholars (e.g., Johnson, 1987; Gibbs, 1994) have adopted cognitive linguistic theories and suggested that idioms are conceptual and compositional in nature. The semantic relationship between idioms and their components is not arbitrary, but motivated by underlying mechanisms such as conceptual metaphors and metonymies (Lakoff, 1987).

The CL-inspired compositional approach promises new and deeper insights into L2 studies of idiom acquisition. It opens new possibilities for innovating teaching design of idioms in L2, and offers learners with alternative strategies in the process of idiom learning. Drawing on the CL perspective, this paper aimed at testifying the efficacy of integrating cognitive linguistic theories in L2 classroom instruction of English idioms. Specifically, it conducted an empirical study to investigate whether and how conceptual metaphor and metonymy might be useful in helping students comprehend English idioms more efficiently. By further differentiating the learning effects of different types of metaphor- and metonymy-based idioms, the study provided a number of findings for L2 acquisition of English idioms.

\section{Literature Review}

2.1 Conceptual Metaphor and Metonymy - A Brief Revisit

What all cognitive linguistic approaches have in common, and what distinguishes them from other approaches, is 
the quest for motivation, which refers to the factors that help explain why a given expression has become conventionalized with a particular meaning or function (Boers, 2014). Lakoff (1987) argued that most idioms are motivated because their meanings make use of certain patterns that have already existed. He claimed that conceptual metaphor, metonymy and conventional knowledge constitute the three relevant motivations in idioms (see also Kövecses \& Szabó, 1996). Since conventional knowledge concerns more with the cultural rather than conceptual dimension, in the first part of this section, we will have a brief revisit of the theories of conceptual metaphor and metonymy.

\subsubsection{Conceptual Metaphor}

According to Lakoff and Johnson (1980), conceptual metaphors bring into correspondence two domains of knowledge. One is typically a well-delineated familiar physical domain (source domain) and the other a less well-delineated, less familiar, abstract domain (target domain). There are generally three types of conceptual metaphors, namely, orientational metaphors, ontological metaphors and structural metaphors (see Table 1).

Table 1. Classification of conceptual metaphors

\begin{tabular}{|c|c|c|}
\hline Type & Definition & $\begin{array}{l}\text { Examples from Lakoff and Johnson } \\
\text { (1980) }\end{array}$ \\
\hline $\begin{array}{l}\text { orientational } \\
\text { metaphors }\end{array}$ & $\begin{array}{l}\text { related to spatial orientations such as up-down, in-out, } \\
\text { front-back, on-off, which can be mapped onto } \\
\text { non-spatial and abstract concepts such as emotion, } \\
\text { health conditions, quantity and social status }\end{array}$ & $\begin{array}{l}\text { MORE IS UP } \\
\text { LESS IS DOWN } \\
\text { HAPPY IS UP } \\
\text { SAD IS DOWN }\end{array}$ \\
\hline $\begin{array}{l}\text { ontological } \\
\text { metaphors }\end{array}$ & $\begin{array}{l}\text { conceptual metaphors in which something non-physical } \\
\text { or abstract such as events, activities, emotions and } \\
\text { ideas are conceptualized metaphorically as entities and } \\
\text { substances or containers }\end{array}$ & $\begin{array}{l}\text { VISUAL FIELD IS A } \\
\text { CONTAINER: } \\
\text { I watched him until he went out of } \\
\text { my sight. } \\
\text { I can't see him-the tree is in the } \\
\underline{\text { way. }}\end{array}$ \\
\hline $\begin{array}{l}\text { structural } \\
\text { metaphors }\end{array}$ & $\begin{array}{l}\text { cases where one concept is metaphorically structured in } \\
\text { terms of another, with the source domain providing a } \\
\text { relatively rich knowledge structure, which is mapped } \\
\text { onto the structure of the target }\end{array}$ & $\begin{array}{l}\text { ARGUMENT IS WAR: } \\
\text { His criticisms were right on target. } \\
\text { If you use that strategy, he will } \\
\text { wipe you out. }\end{array}$ \\
\hline
\end{tabular}

\subsubsection{Metonymy}

The major difference between metonymy and metaphor is that metonymy typically involves one conceptual domain, rather than two distinct domains as in the case of metaphor. Furthermore, metonymy involves a "stand for" conceptual relationship between two entities (within a single domain), while metaphor involves an "is" or "is understood as" relationship between two conceptual domains (Kövecses \& Szabó, 1996). An example can be taken from "hand":

- Hand can be understood as standing for the person:

e.g., a green hand; poor hand; from hand to hand; all hands to the pump

- Hand can be understood as standing for the activity:

e.g., sit on one's hands; join hands with somebody; turn one's hand to something

- Hand can be understood as standing for the skill:

e.g., get one's hand in; one's hand is out; a bad hand at

\subsection{Studies in L2 Idiom Pedagogy}

Following the development of cognitive linguistic theories, the CL-inspired L2 pedagogy of figurative language has been through the exploratory phase during the past several decades (Littlemore, 2009; Tyler, 2012; Niemeier, 2017). There has been an amount of empirical research focusing on L2 idiom teaching and learning from a 
cognitive point of view. Among them, the majority of the studies that applied the conceptual metaphor theory in idiom teaching have confirmed its overall effectiveness (Boers, 2011). For example, Picken (2005) examined whether raising awareness to conceptual metaphors can help Japanese EFL students make sense of linguistic metaphors that are comparatively difficult to identify in context. The study provided evidence that awareness-raising of conceptual metaphors increases the likelihood of metaphoric readings, both in the short and in the longer term. Skoufaki (2008) conducted a small-scale experiment to compare the relative effectiveness of two CL-inspired idiom presentation methods. It was found that encouraging learners to use conceptual metaphor clues to guess the meaning was likely to enhance the effectiveness of presenting metaphoric idioms.

Li (2004) conducted five experiments concerning metaphoric words, idioms and proverbs on 394 Chinese undergraduates of intermediate to advanced levels of English. The first four experiments tested the effect of presenting conceptual metaphor information in the context of (a) a ten-minute discussion with the teacher, (b) being told about conceptual metaphors, and (c) actively engaging with the data. Query routines prompting participants to engage in group discussion were used to facilitate learning and memorization. Li found that the students in the experimental groups who had carried out these activities recalled the form and meaning of the idioms significantly better than those in the control groups, who had been given memory-based tasks.

Though the results of combining the knowledge of metaphor in idiom learning have been largely encouraging, there are still inconsistent findings. Particularly, in a research on English idioms from a view of cognitive semantics, Kövecses and Szabó (1996) found that the participants, when having been introduced to a set of conceptual metaphors, were able to work out the meaning of a totally new set of phrasal verbs. However, they only tested their participants on the particles. When Boers (2000) replicated their study, testing his participants on their ability to understand both parts of the phrasal verbs, it was found that those participants who had received relevant conceptual metaphor training did not significantly outperform those who had received no such training.

In view of the relevant previous studies, it is necessary to probe deeper into the CL-based approach to L2 idiom learning for the following reasons: 1) given the abovementioned conflicts among research findings, there is a need to reexamine the relationship between the knowledge of conceptual metaphors and the meaning of English idioms in the first place; 2) since most of the research took a quantitative way of analysis, there are still plenty of gaps to be filled concerning the varieties of research methods; 3 ) since most studies were engaged in the use of conceptual metaphor in a broad sense, they failed to further explore its differential degrees of effectiveness on different types of metaphoric and metonymic idioms. Hence, will learners truly have a better understanding of idioms when teachers introduce conceptual metaphor and metonymy, and relate them to idioms? Will all kinds of metaphor- and metonymy-based idioms be equally difficult for learners to percept? These are the general questions attempted by this empirical study targeted at Chinese college-level EFL learners.

\section{Methods}

To zero in on the questions proposed in Section 2, an empirical study was conducted to take multi-factors into consideration. It incorporated both the knowledge of conceptual metaphor and metonymy in classroom instruction to investigate their respective effectiveness on idiom learning. Drawing on Lakoff and Johnson's (1980) classification of conceptual metaphors, it further subdivided metaphoric idioms into three corresponding types, so as to distinguish the different degrees of teaching effect on different types of metaphoric idioms. With both quantitative and qualitative methods of data analyses, the ultimate purpose of the study was to gain a comprehensive understanding of the teaching and learning effects on L2 metaphoric and metonymic idioms.

\subsection{Research Questions}

Three research questions were raised:

Q 1: In what ways can the conceptual metaphor-based way of teaching affect the learning of English idioms?

Q 2: Is the conceptual metaphor-based way of teaching equally useful in learning the three types of metaphoric idioms?

Q 3: In what ways can incorporating metonymic knowledge in L2 idiom teaching influence the learning of English idioms?

\subsection{Participants}

The participants, coming from a local leading university located in the southeast part of China, were native speakers of Chinese. They had learned English for more than 8 years and were still attending English classes weekly at college. All the 70 participants were non-English major freshmen. They were from 2 classes of the 
same level. The class set as the experimental group had 36 students and the class as the control group had 34 .

\subsection{Materials}

The idioms that had been chosen were from Lakoff and Johnson (1980), Kövecses and Szabó (1996), Li (2004) and the Oxford Dictionary of Current Idiomatic English. The selected idioms contained no extra unfamiliar vocabulary and were generally not beyond the ability of non-English major freshmen. For the conceptual metaphor part, the following 10 structural and ontological metaphors were chosen in the first part of the test paper (see Table 2). Phrasal verbs containing orientational metaphor of UP and DOWN were used in the second part of the test. For the metonymy part, a series of metonymic uses of HAND were selected. In addition, a group of metonymy-based idioms from Luo (2005) were also used, which served to test the students' ability of applying metonymy to figuring out the meaning of idioms they had not met before.

Table 2. Structural and ontological metaphors used in the first part of the test paper

\begin{tabular}{ll}
\hline LIFE IS A JOURNEY & HEAD IS A MACHINE \\
ANGER IS FIRE & MIND IS A BRITTLE OBJECT \\
AN IDEA IS A PLANT & VISUAL FIELD IS A CONTAINER \\
ARGUMENT IS WAR & INFLATION IS AN ENTITY \\
TIME IS MONEY & ACTIVITIES ARE CONTAINERS \\
\hline
\end{tabular}

\subsection{Instruments}

The whole experiment was divided into 2 sections: one for metaphor-based idiom teaching and the other for metonymy-based idiom teaching. Correspondingly, the test papers were arranged into 2 sections, each section containing a pre-test and a post-test for the experimental group and the control group. The tests for the experimental group and the control group in both sections were the same. The pre-test was conducted to find out the participants' proficiency of idiom learning before different methods were employed. The post-test contained the same number of questions as the pre-test, and the nature of the questions was similar.

In section one (teaching metaphor-based idioms), the test paper was made up of 2 parts. Part one, containing 12 items in all, was to explain the meaning of the underlined idioms in each of the items. The participants were encouraged to write down the meaning or what they thought of the idioms to the best of their knowledge in either Chinese or English. The purpose of this part was not only to find out the students' understanding of the idioms, but also how they tried to figure out the meaning. Structural metaphor- and ontological metaphor-based idioms were mixed and listed in a random order, 6 items for each type. Part two was to complete the phrasal verbs by filling the blanks with UP and DOWN, which included 6 items and was designed to test the students' knowledge of orientational metaphor.

In section two (teaching metonymy-based idioms), the test paper contained only one part, which was to explain the meaning of the idioms in the sentences in a similar way to the first part of section one. There were altogether 10 items in one test. In the test paper, the various metonymic uses of HAND were tested in both the pre- and the post-test, 5 items for each. In addition, another 10 items of metonymy-based idioms were listed in the pre- and the post-test ( 5 for each), with the aim of checking if the students were able to discover the metonymies hidden inside the sentences and deduce the meaning of the idioms from them.

\subsection{Procedures}

The whole experiment was divided into two sections: one for teaching metaphor-based idioms and the other one for teaching metonymy-based idioms. The section for metaphoric idioms was further divided into 3 subsections, each responsible for one type of metaphor. The experiment lasted for 2 months. The students had English classes twice a week. For each class, about 10 to 15 minutes were allotted to teaching and reviewing idioms. In the first month, the instructor introduced structural metaphor, orientational metaphor, ontological metaphor and metonymy, one type each week. In the second month, the instructor spent about 10 minutes reviewing different types of idioms per class. For both groups, the pre-test was taken at the beginning of the first month, and the post-test was taken at the end of the second month. The teaching materials did not overlap with the items on the test paper.

Though the general procedures were the same, the plans of instruction were completely different for the two 
groups. In this study, these two distinctive ways of teaching were named "conceptual metaphor- and metonymy-based ways of teaching" and "traditional way of teaching" respectively. The teaching design for the experimental group and the control group will be elaborated in the following part.

\subsubsection{Experimental Group}

For the experimental group, the knowledge of conceptual metaphor and metonymy was conveyed separately in the two sections. In the first section for metaphoric idioms, the teaching procedures were as follows:

In the beginning of the class, the instructor reminded the students of the traditional view that defines idiom as a single lexical unit whose meaning is not deducible from its separate parts. Several examples such as to kick the bucket and to spill the beans were given and it was pointed out that if we learned idioms simply by rote memorization of the meaning, it would be an extremely tough job to learn English idioms well.

Then, the instructor encouraged the students by telling them that learning idioms did not have to be so difficult and painful, as there was a new method that might be more effective than the traditional ways and make idiom learning much more interesting. The concept of conceptual metaphor was introduced in a simple way, without mentioning those technical terms such as structural or ontological metaphors.

After that, the instructor took the metaphor LOVE IS A JOURNEY as an example. The two related domains were presented, and the instructor told the students that people usually use the knowledge they already know to interpret things that are new to them. Then, typical uses of the metaphor LOVE IS A JOURNEY were shown to the students. The instructor analyzed this example further with a figure of cross-domain mapping in LOVE IS A JOURNEY (see Figure 1).

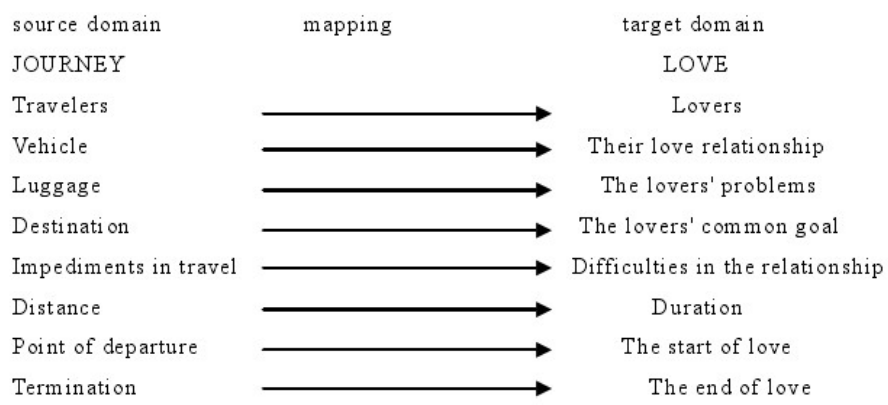

Figure 1. Cross-domain mapping in LOVE IS A JOURNEY (Lakoff, 1993)

Regarding the orientational metaphors, examples were given to the students in diagrams. For instance, in explaining the UP-DOWN orientational metaphor, the instructor showed the students a figure (see Figure 2) for the purpose of enhancing their retention of a series of related usages.

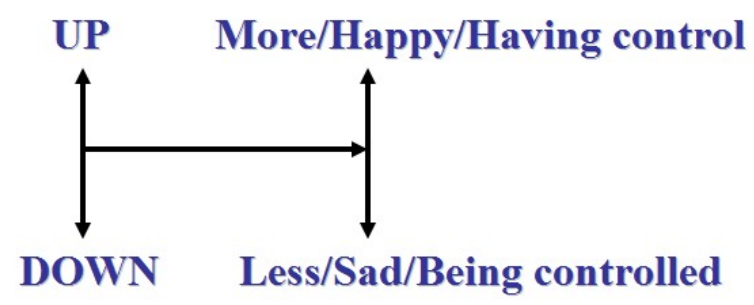

Figure 2. Presentation of the UP-DOWN orientational metaphor

As soon as all the new information was given, the instructor presented a set of idioms that are related to different topics of metaphors (such as LIFE, LOVE and ANGER) in each one class and spent 10 to 15 minutes teaching them. Different forms were used to establish teacher-learner collaboration and avoid monotony in the pattern of teaching. Sometimes, the instructor adopted the way of "query routine" in the following steps: 1) ask the students to make hypothesis about the origin of the expression; 2) refine or rectify their hypothesis; 3) ask the students to interpret the meaning of idioms by combining etymology and context; 4) refine or rectify their interpretation. 
Alternatively, the instructor divided the students into groups and encouraged them to deduce the meaning of idioms on the basis of the shared metaphor.

In the second section for metonymic idioms, the teaching procedures were similar. In addition to the definition of metonymy per se, the difference between metaphor and metonymy was also clarified. In both sections, the students were required to review what they had learned and memorize those idioms with the help of conceptual metaphors and metonymies. An optional homework was to collect new idioms related to the topics discussed in class and try to analyze the underlying metaphors or metonymies. It was hoped that through constant training, the students' metaphoric awareness could be raised bit by bit.

\subsubsection{Control Group}

The design of classroom instruction for the control group followed the traditional method of vocabulary teaching. Since the noncompositional view holds that the meaning of idioms cannot be figured out from the meaning of their constituents, idioms should be treated as chunks that are processed and memorized as a whole. Therefore, for the same teaching materials, the instructor first encouraged the students to guess the meaning of idioms from the contexts, and then told them the correct meaning and asked them to memorize these idioms after class. Both sections of metaphor- and metonymy-based idioms were taught in the similar way.

\subsection{Data Collection and Data Analysis}

In part one of section one, each of the 12 items was scored on a 3-point scale ranging from 0 to 2 . The grading policy was: 1) unanswered items and incorrect answers received 0 points; 2) responses that were partially correct were given 1 point; 3 ) correct meaning explanations got the full 2 points. In part two of section one, 2 points were given to each of the correct answers. With the total number of test items and the range of scores being taken into consideration, each type of idioms had 12 points in all and the full score of the test in section one amounted to 36 points $(3 * 12)$. The same grading policy applied to the test in section two. Each item was attributed 2 points maximum and the whole test $20(2 * 10)$ points in all.

For the sake of convenient calculation, the full score of each test was transformed in proportion into 100 points. Both quantitative and qualitative methods were used in data analysis. SPSS 14.0 was used in the quantitative data analysis. Mean scores and the $\mathrm{p}$ value between the experimental group and the control group in both the pre-test and the post-test were calculated through Independent-Samples T Test. A qualitative way of textual analysis focusing on the individual cases that typically reflected the topic under discussion was also used in this research. The researcher probed into the detailed answers of the participants, trying to analyze their thoughts and see how those answers could be interconnected and offer explanations to the results of the research questions.

\section{Results and Discussion}

This section first presents the results of quantitative data analysis for each research question, and then provides a qualitative textual analysis of the test paper to enrich the findings of the experiments.

\subsection{Quantitative Analysis}

\subsubsection{Research Question One}

Statistical results based on the independent-samples $\mathrm{T}$ test are shown in Table 3. According to the table, the mean scores of the two groups in the pre-test were 60.16 for the experimental group and 58.07 for the control group, which was not significantly different $(p>.05)$. It indicated that before the teaching experiments, the two groups were at the similar level of English proficiency. However, a further comparison of the mean scores in the post-test (66.50 for the experimental group and 60.74 for the control group) revealed that the experimental group performed significantly better than the control group $(p=.000)$. Though there was improvement for both groups during the period of idiom teaching, the progress made by the experimental group was bigger than by the control group. Hence, the results of research question one suggested that the conceptual metaphor-based way of teaching can significantly facilitate the learning of English idioms compared to the cases in which it is not used.

Table 3. Mean scores and $p$ value of the two groups in the pre- and post-test (conceptual metaphor)

\begin{tabular}{llll}
\hline Test type & Experimental (Mean) & Control (Mean) & $p$ (Sig 2-tailed) \\
\hline Pre-test & 60.16 & 58.07 & .069 \\
Post-test & 66.50 & 60.74 & .000 \\
\hline
\end{tabular}




\subsubsection{Research Question Two}

The statistical results of research question two are given in three parts as follows.

First, Table 4 shows the learning effect of structurally metaphoric idioms. The mean scores for the experimental group and the control group in the pre-test (35.61 and 34.10 respectively) were not statistically significant $(p>.05)$. Thus, in the initial stage, the ability of comprehending structurally metaphoric idioms was at the same level for both groups. In the post-test, both groups' mean scores increased: 51.36 for the experimental group and 40.53 for the control group. However, given the similar performance in the pre-test, more progress was made by the experimental group than by the control group, leading to a significant difference of the mean scores in the post-test $(p=.000)$. In view of the better performance of the experimental group after instruction, the metaphor-based way of teaching can significantly help learners comprehend structurally metaphoric idioms.

Table 4. Mean scores and $\mathrm{p}$ value of the two groups in the pre- and post-test (structural metaphor)

\begin{tabular}{llll}
\hline Test type & Experimental (Mean) & Control (Mean) & $p$ (Sig 2-tailed) \\
\hline Pre-test & 35.61 & 34.10 & .372 \\
Post-test & 51.36 & 40.53 & .000 \\
\hline
\end{tabular}

Second, Table 5 presents the results of learning orientationally metaphoric idioms. In the pre-test, the mean scores for the experimental group and the control group were 76.69 and 74.19 respectively $(p=.222)$, indicating that the two groups were almost at the same level of idiom learning. In the post-test, the mean score increased by 1.75 points in the experimental group and 1.21 points in the control group, and the between-group difference was still insignificant $(p=.168)$. It showed that on the one hand, the traditional way of idiom teaching cannot obviously facilitate learning orientationally metaphoric idioms, and on the other hand, applying conceptual metaphor-based way of idiom teaching also cannot significantly help students grasp corresponding idioms.

Table 5. Mean scores and $\mathrm{p}$ value of the two groups in the pre- and post-test (orientational metaphor)

\begin{tabular}{llll}
\hline Test type & Experimental (Mean) & Control (Mean) & $p$ (Sig 2-tailed) \\
\hline Pre-test & 76.69 & 74.19 & .222 \\
Post-test & 78.44 & 75.40 & .168 \\
\hline
\end{tabular}

The last is about teaching ontologically metaphoric idioms. As is shown in Table 6, the situation for ontological metaphor was similar to that for orientational metaphor. In the pre-test, the mean scores were 68.18 (experimental group) and 65.91 (control group), which were not significantly different ( $p>.05$ ). After the two distinctive methods of teaching were applied, in the post-test, a slight improvement was made in both groups, but the between-group difference of mean scores was still not significant. It indicated that neither the traditional teaching method nor the conceptual metaphor-based way of teaching can effectively help with learning ontologically metaphoric idioms.

Table 6. Mean scores and $\mathrm{p}$ value of the two groups in the pre- and post-test (ontological metaphor)

\begin{tabular}{llll}
\hline Test type & Experimental (Mean) & Control (Mean) & $p$ (Sig 2-tailed) \\
\hline Pre-test & 68.18 & 65.91 & .269 \\
Post-test & 69.69 & 66.28 & .051 \\
\hline
\end{tabular}

Therefore, although in a broad sense, the conceptual metaphor-based way of teaching is conducive to learning English idioms, it has different degrees of effectiveness towards different types of metaphoric idioms. While no significant progress was made in learning orientationally and ontologically metaphoric idioms, the students benefited more from the conceptual metaphor-based way of teaching in learning structurally metaphoric idioms. In search of the reason why these differentiated effects existed, it seems that the comprehending difficulty would exert influence to constrain L2 learners' performance in the three types of metaphoric idioms. 
Figure 3 compares the mean scores of the three types of metaphors in the experimental group. In the pre-test, idioms that contained orientational metaphors obtained the highest score, followed by ontologically metaphoric and structurally metaphoric idioms. It suggested that before instruction, orientationally metaphoric idioms were the easiest type and structurally metaphoric idioms were the most difficult type to comprehend. When the experimental group had been treated with the conceptual metaphor-based way of teaching, the mean scores of the three types of idioms increased in the post-test, but the degrees of difficulty remained to be structural $>$ ontological $>$ orientational metaphors.

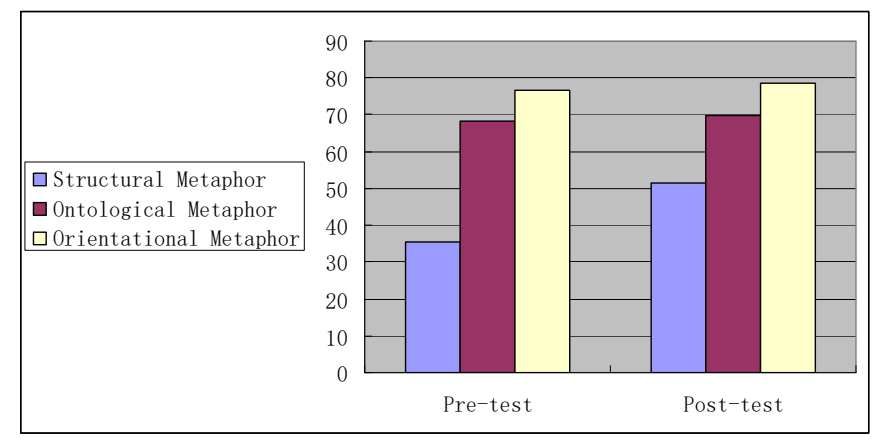

Figure 3. Comparison of the degree of difficulty among the three types of metaphors (experimental group)

The same situation was with the control group (see Figure 4). Though the students in this group learned idioms in the traditional way, the general trend of change in the mean scores was similar to the experimental group. Specifically, orientationally metaphoric idioms were the easiest to grasp, and idioms containing ontological metaphors were easier than structural metaphors in either pre- or post-test.

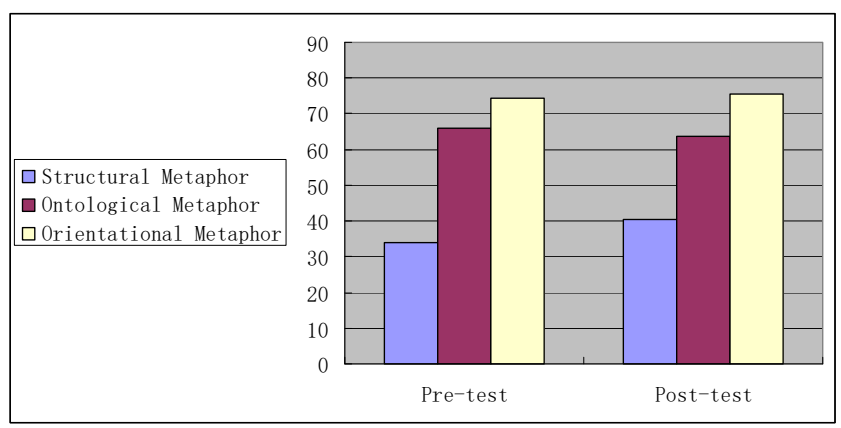

Figure 4. Comparison of the degree of difficulty among the three types of metaphors (control group)

Based on the consistent rank scale of difficulty as analyzed above, it could be seen that the participants from both groups had already been good at comprehending ontologically and orientationally metaphoric idioms in the pre-test. Reasonably, we could surmise that the conceptual metaphor-based way of teaching is significantly helpful in dealing with the idioms that are originally difficult to understand, but is of limited use to those whose meanings are easy to figure out, as learners may encounter a "ceiling effect" in the process of comprehension. Therefore, in terms of the different degree of difficulty in understanding these metaphoric idioms, our conceptual metaphor-based way of idiom teaching is more beneficial to learning structurally metaphoric idioms than to the other two types of idioms.

\subsubsection{Research Question Three}

According to the result of the independent-samples $T$ test (see Table 7), in the pre-test, the mean scores of the experimental group and the control group were 50.33 and 51.40 respectively, the difference of which was not statistically significant $(p>.05)$. Hence, the two groups were at the similar level in comprehending metonymic idioms in the beginning of the experiment. After two months' teaching, the mean scores of the two groups were 59.89 for the experimental group and 47.57 for the control group. The difference between the two groups became 
significant $(p=.000)$.

Table 7. Mean scores and $\mathrm{p}$ value of the two groups in the pre- and post-test (metonymy)

\begin{tabular}{llll}
\hline Test type & Experimental (Mean) & Control (Mean) & $p$ (Sig 2-tailed) \\
\hline Pre-test & 50.33 & 51.40 & .569 \\
Post-test & 59.89 & 47.57 & .000 \\
\hline
\end{tabular}

Noticeably, a comparison of the mean scores revealed an increase of 9.66 points for the experimental group, but a slight drop of 3.83 points for the control group. It indicated that while the participants from the experimental group benefited from the metonymy-based way of idiom learning and made substantial progress, the traditional way of idiom teaching could not help L2 learners comprehend metonymic idioms. Since no obvious difference in the performance was found between the two groups in the pre-test, the experimental group's improvement in the post-test led to the conclusion that incorporating the knowledge of metonymy in L2 idiom teaching can increase the efficiency of learning metonymic idioms than the cases in which it is not used.

\subsection{Qualitative Analysis}

In addition to the statistical analysis, a qualitative scrutiny of the participants' test papers was used to examine the two groups' performance in comprehending different types of metaphoric and metonymic idioms. The participants' answers in the test papers also proved that the conceptual metaphor- and metonymy-based ways of idiom teaching bring more benefits to learners than the cases in which they are not used in L2 idiom learning.

On the one hand, the participants' answers provided evidence that the conceptual metaphor-based way was effective in idiom learning. For example, in the classroom instruction, the teacher told the students that "She was doing a slow burn" and "On hearing that, he starts foaming at the mouth" share a similar metaphor ANGER IS FIRE/INSANITY. In the post-test, two new items containing the metaphor ANGER IS FIRE/INSANITY were given in the paper, i.e., "The low sales volume drove the boss to hit the ceiling at the meeting" and "The loud music has got John to climb the walls". Some students in the experimental group explained the two idioms with exactly the same answer, which suggested that they found out certain common features between the two idioms, and actively linked the new idioms with the metaphors the teacher had taught them before. In contrast, the students in the control group apparently focused more on the literal meaning and transferred the idioms into their false Chinese "counterparts". This kind of mistakes seldom occurred in the experimental group.

On the other hand, concerning the experiment of metonymic idioms, the students' answers also revealed some difference made by the experimental group in the post-test. For instance, during the period of teaching, the instructor told the students that "hand" could have a series of metonymic usages, such as THE HAND STANDS FOR THE ACTIVITY, FOR THE PERSON, FOR THE SKILL, FOR CONTROL, etc. In the post-test, there was an item "The ball was passed from hand to hand", in which "hand" stands for the person who performs the action. In the test paper, some students in the experimental group interpreted from hand to hand as "from one person to another person", or "one by one", which suggested that they were linking body parts to the person as a whole. However, the students in the control group tended to stick to literal translation, for example, paraphrasing the idiom as "the ball was passed from one person's hand to the other person's hand". Though answers of this kind could make sense in this context, they failed to demonstrate a part-whole relationship in language use, which could possibly lead to misinterpretation in other situations.

\section{Conclusion}

This paper has reported on an empirical study that investigated the effects of incorporating conceptual metaphor and metonymy in L2 classroom instruction of English idioms. There are three major findings. First, broadly speaking, the conceptual metaphor-based way of teaching can significantly facilitate learning of English idioms compared to the cases in which it is replaced by the traditional teaching methods. Second, though making use of conceptual metaphor knowledge is helpful for idiom learning, it has different degrees of effectiveness towards different types of metaphoric idioms. While improvement has been detected in learning structurally metaphoric idioms, it has not been obvious regarding orientationally and ontologically metaphoric idioms. Third, the metonymy-based way of teaching is also more conducive to idiom learning than the traditional teaching methods.

Pedagogically, the current study highlights several dimensions in L2 idiom teaching and learning. First, idioms 
are not opaque and solid to such an extent that learners can only resort to the strategy of rote memorization in the learning process. It is thus crucial for teachers to take a positive attitude towards idiom teaching, and pass this spirit on to students to get them prepared for the CL-based methods of idiom learning. Second, since the conceptual metaphor-based way of teaching is not equally helpful in learning different types of metaphoric idioms, more attention should be paid to those idioms that are difficult for students to understand (i.e., the structurally metaphoric idioms), rather than to the relatively easy types such as orientationally and ontologically metaphoric idioms. Given the importance of idiomatic expressions in language use, our effort to integrate the conceptual metaphor- and metonymy-based ways of teaching could facilitate L2 idiom learning practically, and help expand our understanding of figurative language studies in general.

\section{Acknowledgments}

This study has been partially supported by the project (2018SH0023B) "A cognitive linguistic approach to L2 processing of English idiom variation", funded by Shanghai Foreign Language Education Press, P. R. China.

\section{References}

Boers, F. (2000). Enhancing metaphoric awareness in specialised reading. English for Specific Purposes, 19 , 137-147. https://doi.org/10.1016/s0889-4906(98)00017-9

Boers, F. (2011). Cognitive semantic ways of teaching figurative phrases: An assessment. Review of Cognitive Linguistics, 9(1), 227-261. https://doi.org/10.1075/rcl.9.1.11boe

Boers, F. (2014). Idioms and phraseology. In J. Littlemore, \& J. R. Taylor (Eds.), The Bloomsbury companion to cognitive linguistics (pp. 185-201). London: Bloomsbury. https://doi.org/10.5040/9781472593689.ch-011

Celce-Murcia, M., \& Larsen-Freeman, D. (1999). The grammar book: An ESL/EFL teacher's course (2nd ed.). Boston, MA: Heinle \& Heinle.

Cooper, T. C. (1999). Processing of idioms by L2 learners of English. TESOL Quarterly, 33(2), 233-262. https://doi.org/10.2307/3587719

Gibbs, R. W. (1994). The poetics of mind: Figurative thought, language, and understanding. Cambridge: Cambridge University Press.

Irujo, S. (1986). A piece of cake: Learning and teaching idioms. ELT Journal, 40(3), 236-242. https://doi.org/10.1093/elt/40.3.236

Johnson, M. (1987). The body in the mind: The bodily basis of meaning, imagination, and reason. Chicago, IL: University of Chicago Press.

Kövecses, Z., \& Szabó, P. (1996). Idioms: A view from cognitive semantics. Applied Linguistics, 17(3), 326-355. https://doi.org/10.1093/applin/17.3.326

Lakoff, G. (1987). Women, fire, and dangerous things: What categories reveal about the mind. Chicago, IL: University of Chicago Press.

Lakoff, G. (1993). The contemporary theory of metaphor. In A. Ortony (Ed.), Metaphor and thought (pp. 202-251). Cambridge: Cambridge University Press. https://doi.org/10.1017/cbo9781139173865.013

Lakoff, G., \& Johnson, M. (1980). Metaphors we live by. Chicago, IL: University of Chicago Press.

Li, T. (2004). Applied cognitive linguistics: Conceptual metaphor and image schemas in English learning. Beijing: Chinese Cultural and Historical Press.

Liontas, J. (2003). Killing two birds with one stone: Understanding Spanish VP idioms in and out of context. Hispania, 86, 289-301. https://doi.org/10.2307/20062862

Littlemore, J. (2009). Applying cognitive linguistics to second language learning and teaching. Basingstoke, UK: Palgrave Macmillan.

Luo, S. (2005). A research on English idioms. Shanghai: Shanghai Foreign Language Education Press.

Niemeier, S. (2017). Teaching (in) metaphors. In F. Ervas, E. Gola, \& M. G. Rossi (Eds.), Metaphor in communication, science and education (pp. 267-282). Berlin: Mouton de Gruyter. https://doi.org/10.1515/9783110549928-015

Picken, J. (2005). Helping foreign language learners to make sense of literature with metaphor awareness-raising. Language Awareness, 14, 142-152. https://doi.org/10.1080/09658410508668830

Skoufaki, S. (2008). Conceptual metaphoric meaning clues in two L2 idiom presentation methods. In F. Boers, \& 
S. Lindstromberg (Eds.), Cognitive linguistic approaches to teaching vocabulary and phraseology (pp. 101-132). Berlin: Mouton de Gruyter. https://doi.org/10.1515/9783110199161.2.101

Tyler, A. (2012). Cognitive linguistics and second language learning: Theoretical basics and experimental evidence. New York: Routledge.

Zyzik, E. (2011). Second language idiom learning: The effects of lexical knowledge and pedagogical sequencing. Language Teaching Research, 15(4), 413-433. https://doi.org/10.1177/1362168811412025

\section{Copyrights}

Copyright for this article is retained by the author(s), with first publication rights granted to the journal.

This is an open-access article distributed under the terms and conditions of the Creative Commons Attribution license (http://creativecommons.org/licenses/by/4.0/). 